\title{
6S RNA plays a role in recovery from nitrogen depletion in Synechocystis sp. PCC 6803
}

\author{
Beate Heilmann ${ }^{1,4}$, Kaisa Hakkila², Jens Georg ${ }^{3}$, Taina Tyystjärvi², Wolfgang R. Hess ${ }^{3}$, Ilka M. Axmann ${ }^{1 *}$
} and Dennis Dienst ${ }^{1,5}$

\begin{abstract}
Background: The 6S RNA is a global transcriptional riboregulator, which is exceptionally widespread among most bacterial phyla. While its role is well-characterized in some heterotrophic bacteria, we subjected a cyanobacterial homolog to functional analysis, thereby extending the scope of 6S RNA action to the special challenges of photoautotrophic lifestyles.

Results: Physiological characterization of a $6 \mathrm{~S}$ RNA deletion strain $(\Delta s s a A)$ demonstrates a delay in the recovery from nitrogen starvation. Significantly decelerated phycobilisome reassembly and glycogen degradation are accompanied with reduced photosynthetic activity compared to the wild type. Transcriptome profiling further revealed that predominantly genes encoding photosystem components, ATP synthase, phycobilisomes and ribosomal proteins were negatively affected in $\Delta s s a A$. In vivo pull-down studies of the RNA polymerase complex indicated that the presence of $6 \mathrm{~S}$ RNA promotes the recruitment of the cyanobacterial housekeeping $\sigma$ factor SigA, concurrently supporting dissociation of group $2 \sigma$ factors during recovery from nitrogen starvation.

Conclusions: The combination of genetic, physiological and biochemical studies reveals the homologue of 6S RNA as an integral part of the cellular response of Synechocystis sp. PCC 6803 to changing nitrogen availability. According to these results, 6S RNA supports a rapid acclimation to changing nitrogen supply by accelerating the switch from group $2 \sigma$ factors SigB, SigC and SigE to SigA-dependent transcription. We therefore introduce the cyanobacterial 6S RNA as a novel candidate regulator of RNA polymerase sigma factor recruitment in Synechocystis sp. PCC 6803. Further studies on mechanistic features of the postulated interaction should shed additional light on the complexity of transcriptional regulation in cyanobacteria.
\end{abstract}

Keywords: Transcriptional regulation, Small RNA, o factor, RNA polymerase, Cyanobacteria

\section{Background}

Cyanobacteria are photoautotrophic prokaryotes essentially relying on the availability of sunlight and $\mathrm{CO}_{2}$ as their major energy and carbon source, respectively. Due to their autotrophic lifestyle and versatile metabolism, cyanobacteria are suited as economical cellular chassis for diverse biotechnological applications like energy feedstock accumulation [1], third generation biofuel production [2-5] and commodity product biosynthesis [6-8]. However, the

\footnotetext{
* Correspondence: ilka.axmann@hhu.de

${ }^{1}$ Institute for Synthetic Microbiology, Cluster of Excellence on Plant Sciences (CEPLAS), Heinrich Heine University Düsseldorf, Universitätsstrasse 1, 40225 Düsseldorf, Germany

Full list of author information is available at the end of the article
}

long-term mass cultivation for these applications at high cell densities also causes stress conditions that arise from redirecting metabolism, accumulation of potentially toxic compounds and the concomitant tendency for nutrient limitation (reviewed by Dexter et al. [2]). Hence, the requirements for molecular tools and well-defined targets for manipulating the cellular program towards optimized nutrient utilization are of growing interest. Within the diversity of their natural terrestrial and aquatic habitats, cyanobacteria have certainly developed extensive regulatory systems to acclimate to nutrient and light limiting conditions, which are also involving small regulatory RNA molecules (sRNAs, e.g. [9-14]). 
One of the best-characterized prokaryotic sRNA regulators is the widely conserved 6S RNA that responds to changes of the nutritional status [15-18]. When cells of Escherichia coli ( $E$. coli) enter the stationary growth phase, this highly structured RNA specifically regulates transcription by promoter mimicry, as the RNA polymerase (RNAP) holoenzyme carrying the housekeeping sigma factor $\sigma^{70}$ binds to 6S RNA instead of the promoter regions of the household genes [19-22]. Upon nutrient-induced outgrowth from the stationary phase, which includes enhancement of NTP levels, 6S RNA acts as a template for the de novo synthesis of a $\sim 20 \mathrm{nt}$ product RNA (pRNA) [23, 24]. pRNA synthesis triggers the release of 6S RNA from RNAP reverting 6S RNAdependent inhibition [23, 25]. 6S RNA lacking mutants of E. coli and Bacillus subtilis (B. subtilis) show significant phenotypes under long-term nutrient deprivation [20], stress conditions, like alkaline stress $[26,27]$ and during outgrowth from stationary phase [28, 29]. Furthermore, the presence of $6 \mathrm{~S}$ RNA leads to an upregulation of $\sigma^{38}$-activity, while overexpression of 6S RNA in $\sigma^{38}$-deficient cells results in reduced viability in late stationary phase [19].

Homologues of 6S RNA have been identified in several freshwater cyanobacteria, including the model organism Synechocystis sp. PCC 6803 (Synechocystis 6803) [15, 30, 31]. While in vitro studies indicate a conservation of basic 6S RNA mechanisms like transcription inhibition and pRNA synthesis, little is known about the functional relevance of the cyanobacterial 6S RNA in vivo [32].

Since phototrophic growth of cyanobacteria does essentially rely on atmospheric or enriched $\mathrm{CO}_{2}$ supplementation and - importantly - light, plain dilution experiments would rather evoke responses to changing light availability (and its relation to $\mathrm{CO}_{2}$ availability). Accordingly, a specified experimental setup was required for functional characterization of cyanobacterial 6S RNA during outgrowth from nutritional deprivation. Regarding the status of an inorganic nitrogen source - i.e. nitrate or ammonia - non-diazotrophic cyanobacteria like Synechocystis 6803 exhibit a well-controlled acclimation behavior that is also accompanied by a stationary growth plateau [33]. Acclimation of cyanobacteria to changing nitrogen availability is a tightly controlled process that has been well described in the literature. One of the most pronounced physiological responses is the remodeling of the photosynthetic machinery, leading to distinctly and visibly reduced amounts of the phycobilisome antenna complex and - delayed in time - chlorophyll $a$ breakdown [33-36]. These biochemical mechanisms are influenced by elaborate underlying events of gene expression control. This network essentially involves the collaborative action of the global transcriptional regulator NtcA and the proteins PII and PipX [37].
Moreover, several group $2 \sigma$ factors appear to play a role within the nitrogen regulatory network. Besides the nitrogen stress response $\sigma$ factor SigE, these are $\mathrm{SigB}$, involved in the NtcA-dependent nitrogen-related gene expression during exponential growth and SigC, in the response of stationary phase cultures to nitrogen starvation [38-40].

Several reports described the transcriptomic characteristics of nitrogen-starving cyanobacteria [41, 42] as well as the response upon nitrogen repletion in a timeresolved manner [36, 43]. The recovery process after long-term starvation is initiated by the upshift of respiratory gene expression and switching on the translational machinery as well as nitrogen assimilation. Further, until full physiological restoration, the cells successively reactivate photosynthetic complexes, carboxysomes and the cell division machinery [43]. Cells without any group $2 \sigma$ factors are not able to recover from nitrogen deficiency [40].

Here we describe the involvement of the sRNA regulator 6S RNA in the dynamics of nitrogen acclimation in Synechocystis 6803, elaborating the example of $\mathrm{NO}_{3}^{-}$-mediated recovery from long-term nitrogen starvation.

\section{Results}

Inactivation of 6S RNA affects photosynthetic parameters and storage of carbohydrates upon nitrogen starvation and recovery

To analyze the functional role of $6 \mathrm{~S}$ RNA in cyanobacteria, we deleted the $s s a A$ gene encoding 6S RNA from the genome of Synechocystis 6803. The ssaA gene was replaced with a kanamycin resistance cassette (Fig. 1a) and complete segregation of the resulting $\triangle s s a A$ mutant was confirmed by colony PCR (Fig. 1b) as well as by Northern Blot analysis (Fig. 1c).

Under standard growth conditions, the $\Delta s s a A$ strain did not show any clear phenotype. Referring to 6S RNA function in E. coli and B. subtilis, where it regulates RNAP activity during the stationary growth phase and outgrowth $[17,18]$, the following mutant characterization experiments were conducted under nitrogen depletion (which leads to a stationary state of cell culture) and subsequent recovery by repletion with $17.6 \mathrm{mM} \mathrm{NaNO}_{3}$ (corresponding to outgrowth).

The acclimation to nitrogen depletion proceeded similarly in the $\triangle s s a A$ strain as in wild type (WT), demonstrated by similar whole-cell absorption spectra of $\triangle s s a A$ and WT cells after seven days of nitrogen deficiency (Fig. 2c, $0 \mathrm{~h}+\mathrm{N}$ samples; Additional file 1: Figure S1a). Furthermore, light-saturated photosynthetic activities (Additional file 1: Figure S2a) and $77 \mathrm{~K}$ fluorescence spectra (Additional file 1: Figure S2b) were similar in both strains in the middle of the nitrogen deficiency treatment. 

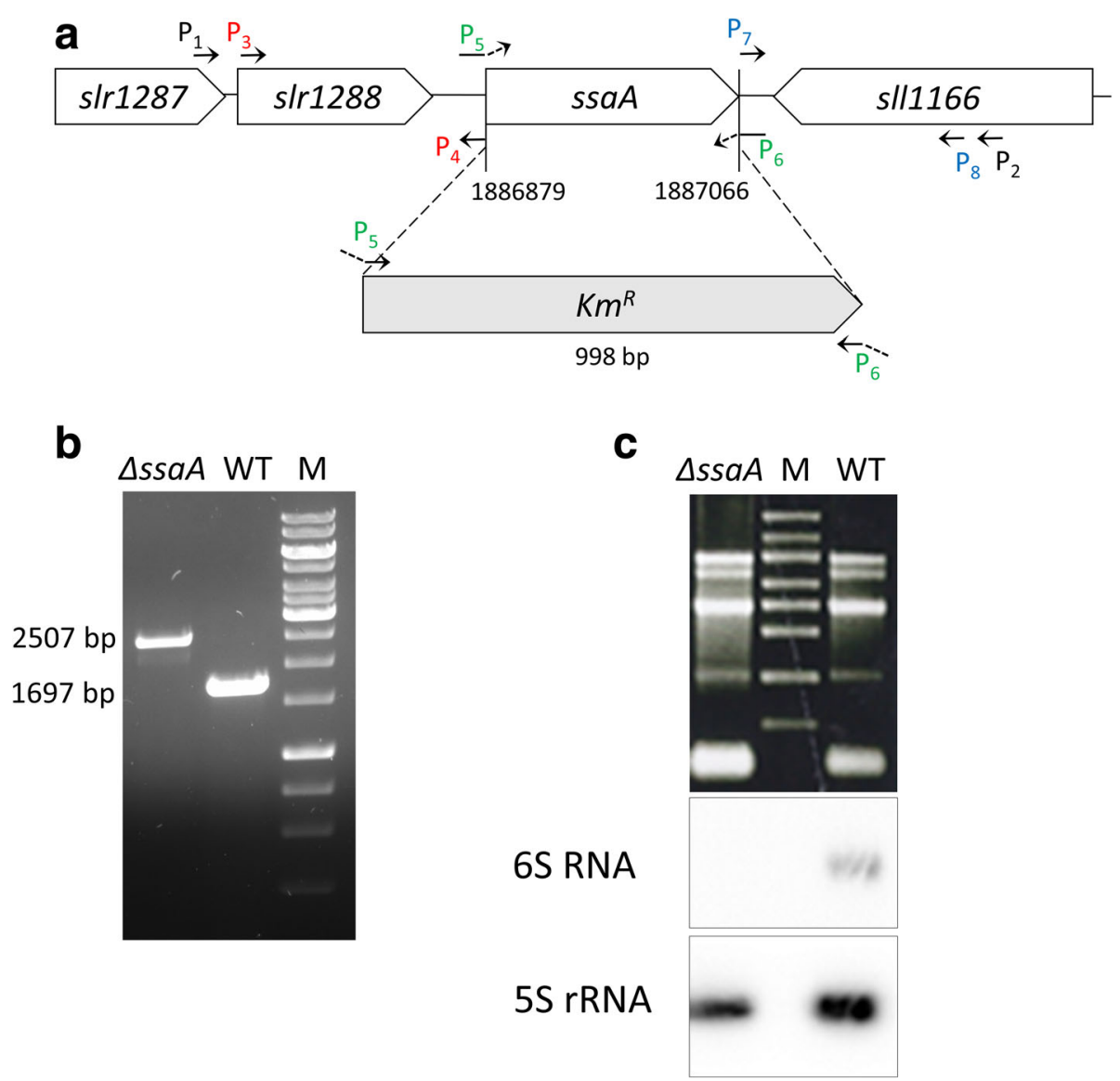

Fig. 1 Strategy and confirmation of the Synechocystis $6803 \Delta s s a A$ mutant. a Strategy for the construction of the $\Delta s s a A$ mutant. The ssaA gene was replaced by a kanamycin resistance cassette $\left(\mathrm{Km}^{\mathrm{R}}\right)$ and its promoter region (grey box) at the indicated genome position (ssaA locus: 1,886,879... 1,887,066). The construction was realized by overlap extension PCR of three fragments using primer pairs P3 and P4 (red), P5 and 6 (green, P5: 15 bp 5'-end overlap with P4, 17 bp 3'-end overlap with Km ; P6: 14 bp 5'end overlap with P7, 24 bp 3'end overlap with Km ${ }^{R}$ ) and P7 and P8 (blue). The construct was further used to replace ssaA in the genome of Synechocystis 6803 by homologous recombination. P1 and P2 represent the location of primers used to verify complete segregation of the mutant strain. The location of genes s/r1287, s/r1288 and s/11 166 are depicted upstream and downstream of the $s s a A$ gene. $\mathbf{b}$ Complete segregation of the $\Delta s s a A$ mutant gene copies and replacement with a kanamycin resistance cassette (Km $\left.{ }^{R}\right)$ and its flanking regions (998 nt) was tested by PCR analysis, using primers P1 and P2. c Deletion of 6S RNA in $\triangle$ ssaA mutant was confirmed by Northern blot analysis using a radioactive $\left[{ }^{32} \mathrm{P}\right]$-labelled oligonucleotide for $65 \mathrm{RNA}$. $5 \mathrm{~S}$ rRNA was hybridized as a loading control

Visible differences between the strains were detected during the recovery phase. After $22 \mathrm{~h}$ of recovery, WT showed normal green color of a viable Synechocystis 6803 culture while the $\Delta s s a A$ mutant still remained yellow-orange, which is a typical characteristic of nitrogen depleted cultures (Fig. 2a).

Whole-cell absorption spectra were measured to follow changes in all major photosynthetic pigments. The color of nitrogen depleted cells is due to prominent loss of blue phycobilins (absorption maxima at $620-635 \mathrm{~nm}$ ), clear loss of green chlorophyll $a$ (Chl $a$, absorption maxima at $680 \mathrm{~nm}$ ), but only minor reduction of yellow-orange carotenoid pigments (Fig. 2c; compare $0 \mathrm{~h}+\mathrm{N}$ and the fully recovered $144 \mathrm{~h}+\mathrm{N}$ samples). Re-synthesis of pigments takes hours after nitrogen supply. In both strains phycobilin (Fig. 2c) and Chl $a$ (Fig. 2b and c) contents remained low after $4 \mathrm{~h}$ of recovery. After $22 \mathrm{~h}$ both phycobilins and Chl $a$ showed significant retrieval in WT while in $\Delta s s a A$, the recovery process was still in an early stage (see Additional file 1: Figure S1 for pairwise comparison of WT and $\Delta s s a A$ at each time point). According to statistical analysis (one-way ANOVA), the Chl $a$ content was significantly lower in $\Delta s s a A$ than in WT at $22 \mathrm{~h}+\mathrm{N}$ $(p=0.0067)$. A delay in phycobilisome reconstruction in $\triangle s s a A$ was also seen as reduced accumulation of the main phycobiliproteins, phycocyanin and allophycocyanin, after $22 \mathrm{~h}$ of nitrogen repletion (Additional file 1: Figure S4a and $\mathrm{b})$. The phycocyanin content was significantly lower in $\Delta s s a A$ than in WT at $22 \mathrm{~h}+\mathrm{N}(p=0.0183$, one-way ANOVA; Additional file 1: Figure S4a). However, $\Delta s s a A$ cells completely recovered over extended periods of $48 \mathrm{~h}$ or longer (Fig. 2b and c). A $\Delta s s a A$ complementation strain 
a

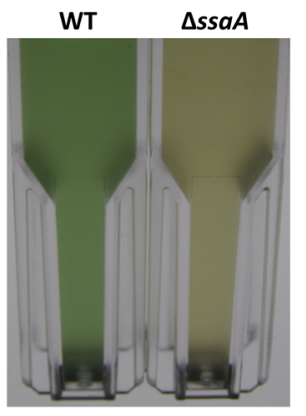

C

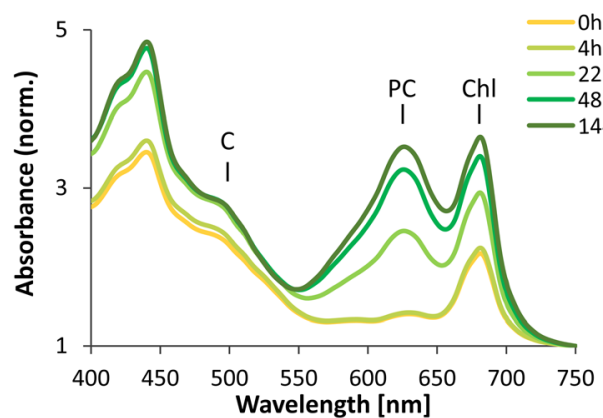

b

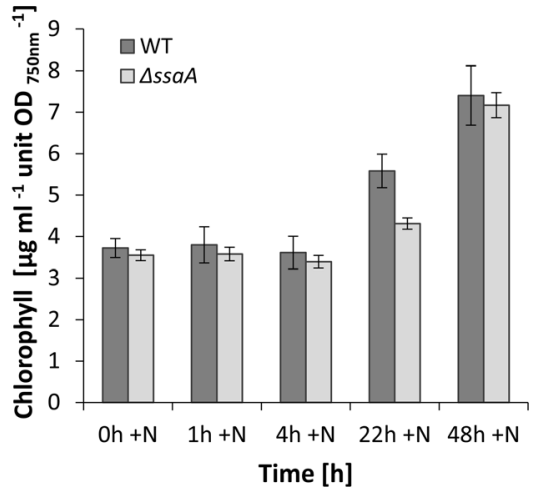

$\Delta s s a A$

Fig. 2 Comparative physiological characterization of the Synechocystis 6803 WT and $\Delta$ ssaA mutant strain and phenotype studies of the mutant strain. Cultures were grown under continuous white light at an irradiance of $80 \mu \mathrm{mol}$ photons $\mathrm{m}^{-2} \mathrm{~s}^{-1}$, at $30^{\circ} \mathrm{C}$, in nitrogen-depleted medium for $189 \mathrm{~h}$ before recovery was initiated by adding nitrogen. a Photograph of cultures of Synechocystis 6803WT and $\Delta$ ssaA mutant strain during recovery from nitrogen starvation, $t=22 \mathrm{~h}+\mathrm{N}$. Cultures were adjusted so that their cell densities were the same (as estimated by the $\mathrm{OD}_{750}$ ), transferred to 1$\mathrm{cm}$ cuvettes, and photographed with illumination from behind. b Chlorophyll content of Synechocystis $6803 \mathrm{WT}$ and $\Delta$ ssaA measured after cultivation in nitrogen deficiency for $189 \mathrm{~h}(t=0 \mathrm{~h}+\mathrm{N})$ and at recovery time points $t=1 \mathrm{~h}, t=4 \mathrm{~h}, \mathrm{t}=22 \mathrm{~h}$ and $t=48 \mathrm{~h}(+\mathrm{N})$. The illustrated data represent the mean from three independent biological replicates and the standard deviation was calculated. c Details of whole cell absorbance spectra of Synechocystis $6803 \mathrm{WT}$ and $\Delta s s a A$ strains are shown for the time point $\mathrm{t}=0 \mathrm{~h}+\mathrm{N}$, which corresponds to $189 \mathrm{~h}$ under nitrogen deficiency $(-\mathrm{N})$ and for the time points $\mathrm{t}=4, \mathrm{t}=22, \mathrm{t}=48$ and $t=144 \mathrm{~h}$ after nitrogen addition $(+\mathrm{N})$. The spectra were normalized at $750 \mathrm{~nm}$. C: carotenoids; PC: phycocyanine; Chl: chlorophyll $a$

( $\triangle s s a A-c)$, which expresses the native $s s a A$ gene from a self-replicative vector, recovered from the nitrogen deficiency similarly as WT (Additional file 1: Figure S3), confirming that this phenotype is a specific result from the absence of 6S RNA, rather than from polar effects.

To further compare the recovery of the photosynthetic reaction centres and light harvesting complexes of the strains, we measured $77 \mathrm{~K}$ fluorescence spectra using orange light phycobilisome excitation $14 \mathrm{~h}$ after nitrogen addition. This time point was selected because in the experimental setup the chlorotic lag of $\triangle s s a A$ was apparent particularly during the period between $12 \mathrm{~h}$ and $24 \mathrm{~h}$ after addition of nitrate. The lower peaks originating from phycobilisome rods $(648 \mathrm{~nm})$ and cores $(665 \mathrm{~nm})$ in $\triangle s s a A$ cells indicate lower amounts of both phycocyanin and allophycocyanin in the mutant strain, thus confirming the decelerated recovery of phycobilisome antenna in the mutant (Fig. 3a). In addition, the ratio of $\mathrm{CP} 47$ peak (originates from the inner antenna protein
CP47 of PSII) at $\sim 694 \mathrm{~nm}$ to CP43 peak (originates from the terminal emitter of the phycobilisome antenna and from the PSII inner antenna protein CP43) at $\sim 658-686 \mathrm{~nm}$ was lower in the $\Delta s s a A$ mutant than in WT, indicating reduced efficiency of light harvesting for PSII in $\triangle s s a A$ (Fig. 3a). In accordance with that the light-saturated PSII and photosynthetic activities were 10 to $15 \%$ lower in $\triangle s s a A$ than in WT after $22 \mathrm{~h}$ of recovery in nitrogen replete conditions (Fig. 3b and c). However, due to high variations between biological replicates these differences between the strains are not statistically significant.

Since nitrogen starvation limits consumption of carbon skeletons, starved Synechocystis 6803 cells store carbon polymers like glycogen. Under nitrogen starvation both strains stored similar amounts of glycogen (Additional file 1: Figure S5). After nitrogen addition glycogen decreased in both strains, where a delayed degradation in $\triangle s s a A$ is indicated by comparatively high 

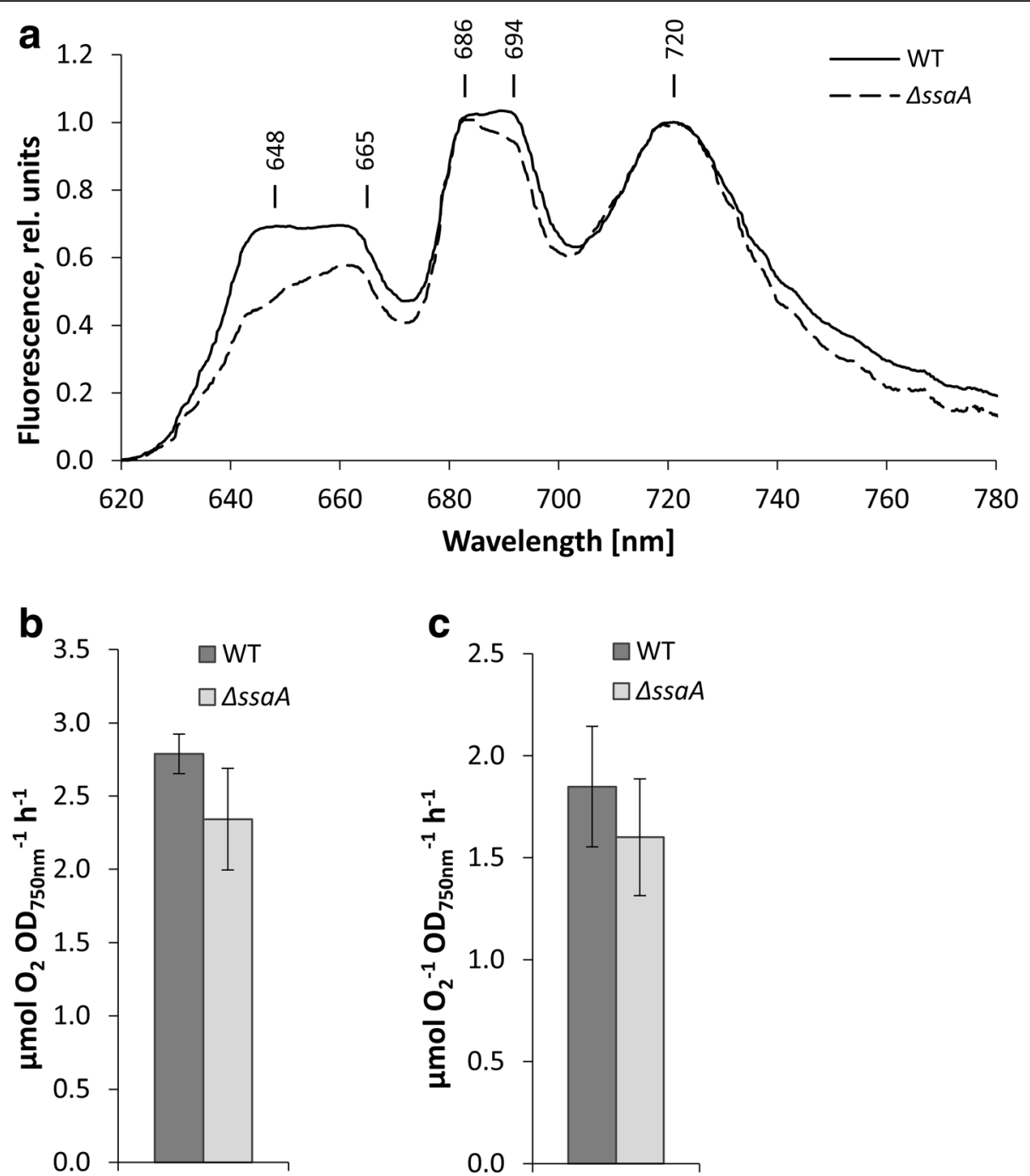

Fig. 3 Photosynthetic parameters of WT and $\triangle s s a A$ mutant during recovery from nitrogen starvation. a Orange light-excited fluorescence emission spectra of WT and $\triangle$ ssaA mutant at $77 \mathrm{~K}$ after $14 \mathrm{~h}$ of recovery $(+\mathrm{N})$. The spectra were normalized by dividing by the peak value of PSI at $721 \mathrm{~nm}$ and setting this value to 1. Oxygen evolution rates of electron transport in PSII (b) and photosynthesis (c) measured in vivo at time point $16-22 \mathrm{~h}+\mathrm{N}$ under light-saturated conditions (3000 $\mu \mathrm{mol}$ photons $\mathrm{m}^{-2} \mathrm{~s}^{-1}$ ). Three independent biological replicates were measured and the error bars represent the standard deviation

levels after $22 \mathrm{~h}$ (Additional file 1: Figure S5). Our results indicate that although 6S RNA is not completely essential for the cells to recover from nitrogen starvation, the presence of $6 \mathrm{~S}$ RNA accelerates the recovery process for hours.

Further investigation was carried out to analyze the $6 \mathrm{~S}$ RNA transcript level under nitrogen starvation and recovery. Northern Blot analysis of 6S RNA revealed that the accumulation of 6S RNA increased in WT in the course of long term $(189 \mathrm{~h}-\mathrm{N})$ nitrogen depletion by $\sim 40-55 \%$ and returned to the original level, when normalized to $5 \mathrm{~S}$ rRNA levels (Fig. 4a). However, since ribosomal RNA is rather expected to decrease during chlorosis [44] and consequently to increase again during recovery, $6 \mathrm{~S}$ RNA accumulation is rather constant or slightly upregulated (Fig. 4a).
Interestingly, overexpression of $6 \mathrm{~S}$ RNA, as implemented in the $6 \mathrm{~S}(+)$-mutant, did not further accelerate recovery after nitrogen depletion (Fig. $4 \mathrm{~b}$ and c).

6S RNA accelerates expression of household genes upon recovery from nitrogen starvation

Comparative transcriptome analysis was performed to infer a functional signature from the mutant-specific transcript profiles (raw data is available in Additional files 2 and 3). For this purpose, microarray analysis was used to probe total RNA from WT and $\triangle s s a A$ cultures that were starved for nitrogen for seven days and recovered over a period of $22 \mathrm{~h}$. Sampling time points were $\mathrm{t}_{1}=0 \mathrm{~h}\left(7 \mathrm{~d}-\mathrm{N}\right.$; reference), $\mathrm{t}_{2}=1 \mathrm{~h}+\mathrm{N}, \mathrm{t}_{3}=4 \mathrm{~h}+\mathrm{N}$ and $t_{4}=22 \mathrm{~h}+\mathrm{N}$. At $\mathrm{t}_{1}=0 \mathrm{~h}$ a total set of 65 features 


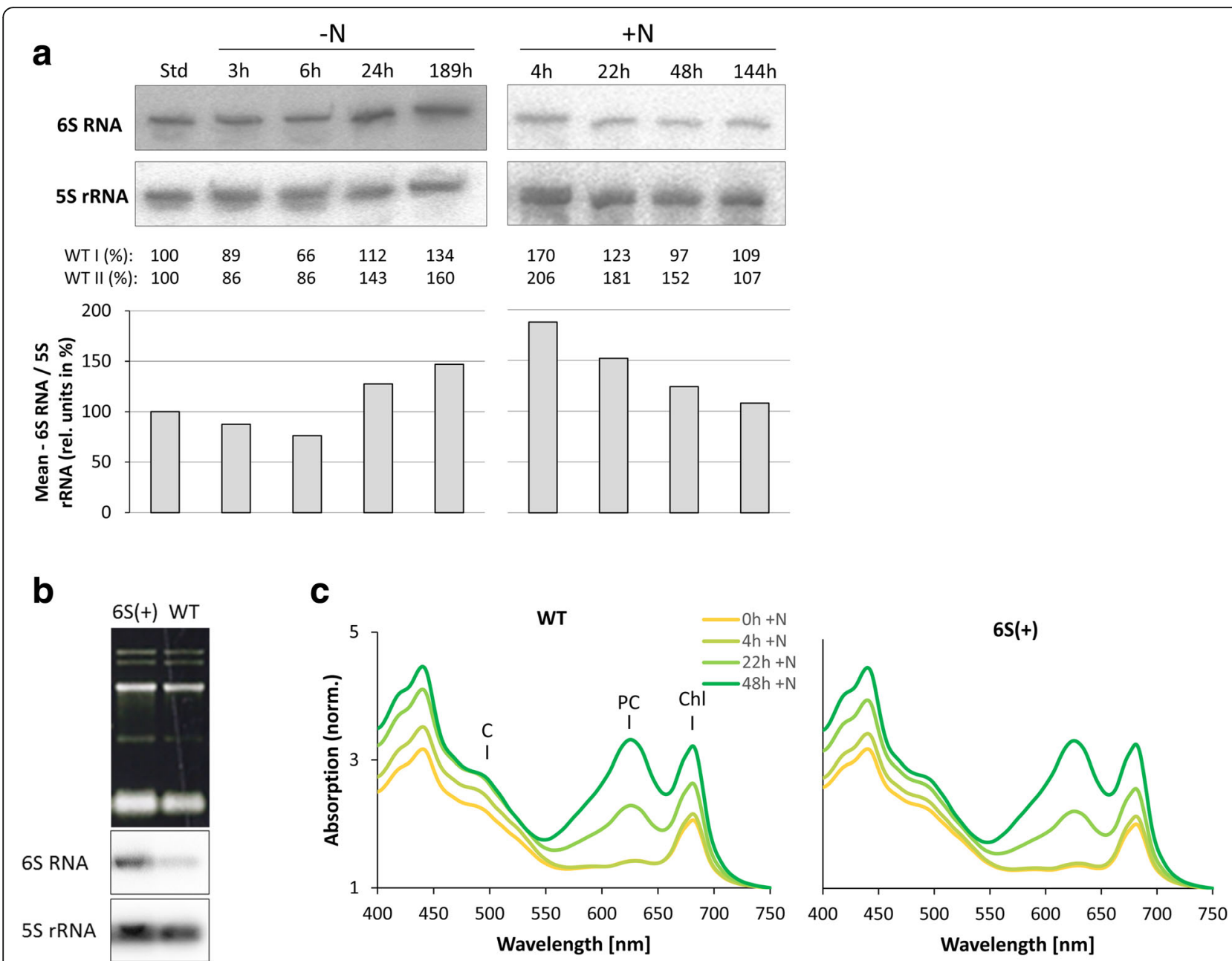

Fig. 4 Analysis of 6S RNA transcript levels during nitrogen starvation and recovery in Synechocystis 6803 WT (a) and physiological characterization of the Synechocystis 6803 mutant strain overexpressing 6S RNA (6S(+)) (b and $\mathbf{c})$. a Total RNA was isolated from cell cultures grown at standard growth conditions $(t=S t d)$, under nitrogen depleted conditions $(t=3 \mathrm{~h}-\mathrm{N}, t=6 \mathrm{~h}-\mathrm{N}, t=24 \mathrm{~h}-\mathrm{N}, t=189 \mathrm{~h}-\mathrm{N})$ and under nitrogen replete conditions $(\mathrm{t}=4 \mathrm{~h}+\mathrm{N}, \mathrm{t}=22 \mathrm{~h}+\mathrm{N}, \mathrm{t}=48 \mathrm{~h}+\mathrm{N}, \mathrm{t}=144 \mathrm{~h}+\mathrm{N})$ and samples with $5 \mu \mathrm{g}$ RNA were analyzed by Northern blot hybridization. Autoradiograms are illustrated for WT I. 6S RNA and 5S rRNA signals of two biological replicates (WT I, WT II) were quantitated and 5S rRNA signal was used as an internal reference. The mean values are illustrated in the chart. Values of $\mathrm{t}=\mathrm{Std}$ were set to 100 and samples of all other time points were calculated, respectively. $\mathbf{b}$ Northern Blot analysis to confirm overexpression of $6 \mathrm{~S}$ RNA in 6S(+) mutant. 2 $\mu \mathrm{g}$ of total RNA was separated by electrophoresis on $1.3 \%$ agarose-formaldehyde gel. The amount of $6 \mathrm{~S}$ RNA and $5 \mathrm{~S}$ rRNA was detected by using radioactive $\left.{ }^{32} \mathrm{P}\right]$-labeled oligonucleotides. $\mathbf{c}$ Physiological characterization of the $6 \mathrm{~S}(+)$ strain. Absorbance spectra of the Synechocystis 6803 wild-type and the $6 \mathrm{~S}(+)$ strain are illustrated for the time points $\mathrm{t}=0 \mathrm{~h}+$ $\mathrm{N}, \mathrm{t}=4 \mathrm{~h}+\mathrm{N}, \mathrm{t}=22 \mathrm{~h}+\mathrm{N}$ and $\mathrm{t}=48 \mathrm{~h}+\mathrm{N}$. The spectra were normalized at $750 \mathrm{~nm}$. C: carotenoids; PC: phycocyanine; Chl: chlorophyll $a$

showed differential accumulation (log2 fold change (FC) of $>1$ (adjusted $p$-value of $\leq 0.05$ ) in $\Delta s s a A$, the majority of which were downregulated. Most of the latter comprised non-coding transcripts like asRNAs, but also eight mRNAs showed lower levels. Among them were several mRNAs encoding subunits of ATP synthase, the mRNA for cell division protein SepF as well as ferredoxin encoding petF and the high-light inducible hliA. The positively regulated genes included the heat stress responsive histidine kinase hik34 and the chaperone encoding genes $d n a J$ and groEL-2 (Additional file 1: Figure S6).
Temporally altered transcript levels in $\triangle s s a A$ from $\mathrm{t}_{1}=0 \mathrm{~h}$ to all three analyzed time points of recovery were plotted as a function of the corresponding temporal changes in WT, distinctively comparing the recovery in both strains (Additional file 1: Figures S7-S9). Comparison of transcript profiles indicated that only few genes were activated or repressed in the early phase of recovery, whereas $22 \mathrm{~h}$ after addition of nitrogen, numerous genes responded, most of which were upregulated (Additional file 1: Figure S9).

Normalized expression values of selected groups of functionally related genes have been standardized to be 
able to compare the expression patterns changes of genes with different expression levels and are further depicted in time courses in Fig. 5a-f. In WT cells transcriptional upshift of ATP synthase genes was seen already $1 \mathrm{~h}$ after nitrogen addition and continued for whole recovery phase (Fig. 5a). In $\Delta s s a A$, upregulation of atp transcripts was delayed, keeping atp transcripts at low levels for the first $4 \mathrm{~h}$. However, these differences between both strains vanished after $22 \mathrm{~h}$ of recovery (Fig. 5a). Likewise, the transcriptional upshift of ribosomal subunits was delayed in $\triangle s s a A$ (Fig. 5b).
During the first $4 \mathrm{~h}$ after nitrogen repletion many genes encoding proteins for the major photosynthetic complexes photosystem I ( $p s a$ genes, Fig. 5e), photosystem II (psb genes, Fig. 5f) and light harvesting phycobilisome antenna genes (Fig. 5c) produced less transcripts in $\triangle s s a A$ than in WT. After $22 \mathrm{~h}$ of recovery these effects were not that clear anymore. For genomic context of $a p c$ and $c p c$ operons, see Additional file 1: Figure S10. Altogether, the transcriptomics data is in good agreement with the delayed physiological response of the mutant as reflected by the data shown in Figs. 2 and 3.
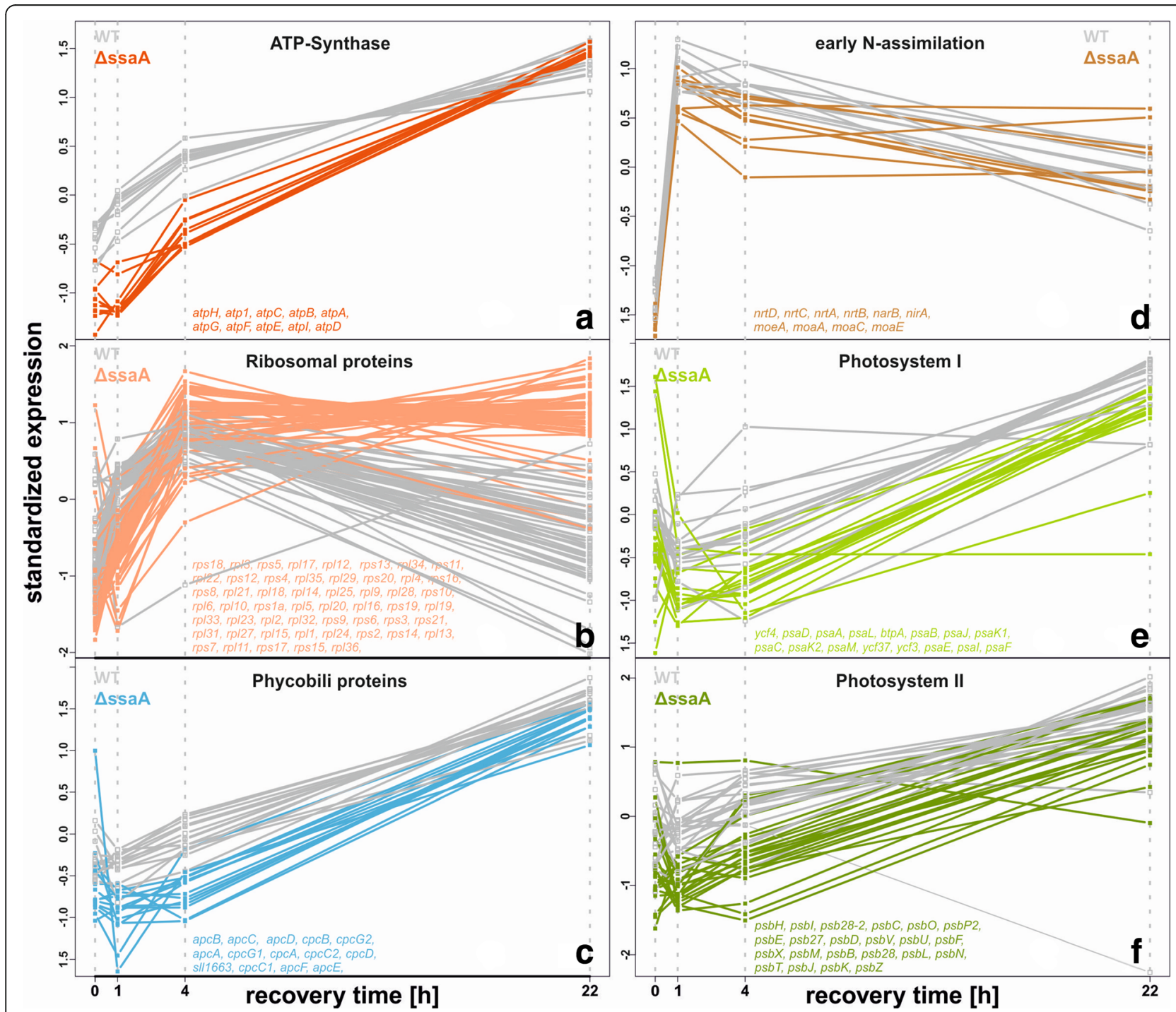

Fig. 5 Temporal response of functional groups to nitrogen re-addition in the WT and $\Delta s s a A$. Transcriptional profile of genes related to ATP synthase (a), ribosomal proteins $(\mathbf{b})$, phycobili proteins $(\mathbf{c})$, early nitrogen assimilation $(\mathbf{d})$, PSI $(\mathbf{e})$ and PSII (f) are grouped respectively. (x-axis) time after nitrogen addition. (y-axis) standardized normalized gene expression. To be able to compare the dynamics of the different genes in one plot the expression levels were standardized gene wise for both strains together, so that the average expression value is 0 and the standard deviation is one. WT expression is shown in grey and colored for $\Delta s s a A$. The color code refers to the displayed functional categories (red: ATP-synthase, salmon: Ribosomal proteins, cyan: Phycobili- proteins, brown: N-assimilation, light green: Photosystem I, dark green: Photosystem II). For comparability the same color code is used in (Figs. S7-9). The genes which are plotted for each group are indicated in each sub-figure 
Notably, levels of important 'marker' transcripts of nitrogen recovery encoding components of the nitrate uptake $(n r t A B C D)$ and early assimilation machinery (narB, nirA, moaACE) increased rapidly in both strains (Fig. $5 \mathrm{~d})$. Over the complete period, abundance of e.g. nitrate reductase encoding nirA kept stable in the mutant, whereas a moderate decline after the first hour was observed for all transcripts in the WT and likewise - for the majority of this group - in $\triangle s s a A$ (Fig. $5 \mathrm{~d}$ ).

For possible transcriptional regulators, we focused on genes encoding the regulatory $\sigma$ factors. The $\operatorname{sig} A$ transcript (encoding primary $\sigma$ factor SigA) was upregulated in $\Delta s s a A$ compared to WT after $4 \mathrm{~h}$ of recovery, while transcripts for group $2 \sigma$ factors $\mathrm{SigB}$ and $\mathrm{SigC}$ were slightly up at all time points in the mutant. Levels of sigG, encoding an ECF-type $\sigma$ factor, were slightly down (Fig. 6a-g). Note that the mRNA accumulation of $\sigma$ factor encoding genes cannot be considered a measure of $\sigma$ factor recruitment by RNAP, but rather an effect of the latter.

In addition to protein-coding genes, a few small noncoding RNAs (sRNAs) showed altered levels in the mutant, including the previously characterized PmgR [45], NsiR4 and PsrR1 [11], as well as several hypothetical riboregulators that were identified by differential RNA sequencing (dRNA-seq) [46]. Among these transcripts, SyR11 exhibited the most diverging accumulation kinetics (Fig. 6h; see also Northern Blot validation in Additional file 1: Figure S11). Additionally, Fig. 6i-k illustrate the mRNA abundances of three exemplarily selected transcripts ( $p s a M, p s b K, p s b M$ ) of PSI and PSII, revealing the decelerated upregulation of components of the photosynthetic apparatus in $\Delta s s a A$ in detail.

\section{S RNA influences the allocation of SigA, SigB, SigC and SigE in the RNA polymerase holoenzyme}

We next studied if the absence of 6S RNA influences the content of the primary or group $2 \sigma$ factors and/or recruitment of different $\sigma$ factors by the RNAP core to form the holoenzyme during nitrogen starvation and recovery phase. To that end, the $\gamma$-subunit of RNAP core was replaced with His-tagged $\gamma$-subunit in WT and $\Delta s s a A$ as described recently for a non-motile Synechocystis 6803 strain [47]. The WT RNAP-His and $\Delta s s a A$ RNAP-His strains were grown under standard conditions or subjected to nitrogen depletion for 6 days; recovery samples were taken $1 \mathrm{~h}, 4 \mathrm{~h}$ or $22 \mathrm{~h}$ after nitrogen addition. The His-tagged RNAP complexes were collected from one-half of each sample and the soluble proteins were isolated from the other half.

To measure possible changes in SigA content and/or in recruitment efficiencies by the RNAP core, isolated soluble proteins and collected RNAP complexes were separate on SDS-PAGE, respectively. Subsequently, the SigA content was detected using a SigA specific antibody
[47]. Then membranes were re-probed with the antibody against the $\alpha$ (or $\beta$ ) subunit of the RNAP core and the SigA content was normalized to the RNAP core content. Finally, after each treatment, the amount of SigA was compared to the amount of SigA in cultures from standard (nitrogen replete) conditions. SigA almost vanished from the RNAP holoenzyme during nitrogen depletion in both strains (Fig. 7a), but SigA protein content decreased by only $65 \%$ (Fig. $7 \mathrm{~b}$ ) indicating that the recruitment of SigA by RNAP core reduced more drastically than SigA content. After nitrogen addition, RNAP core progressively recruited more SigA (Fig. 7a). The recovery of the SigA recruitment occurred more slowly in $\Delta s s a A$ than in WT (Fig. 7a), although the SigA content increased more rapidly during recovery in $\triangle s s a A$ than in WT (Fig. 7b). Poor recruitment of SigA in $\triangle s s a A$ is an obvious reason for slow activation of household genes in this strain.

When group $2 \sigma$ factors were analyzed, using the same method as described for the primary $\sigma$ factor, the results showed that in nitrogen starved WT cells $(0 h+N)$ both recruited and total SigB remained at the same level as under standard conditions (Fig. 7c and d). Although the total amount of SigB decreased moderately during the recovery period, this $\sigma$ factor was recruited in particular during the early recovery phase (Fig. $7 \mathrm{c}$ and $\mathrm{d}$ ). In $\triangle s s a A$, SigB was more efficiently recruited by RNAP core both under standard conditions and during early recovery than in WT (Fig. 7c and d). Thus, the presence of 6S RNA seems to restrict recruitment of SigB by the RNAP core. Like SigB, SigC was highly recruited during recovery phase, however SigC was already recruited efficiently in nitrogen depleted cells (Fig. 7e and f). Very high levels of SigC recruitment were observed in the mutant strain at early time points of recovery. The amount of SigD was very low or below detection limit in all samples and quantification of SigD results was not possible. Unlike the other $\sigma$ factors, the SigE protein content was clearly higher in nitrogen depleted samples, which was also observed in samples from the early recovery phase. Increased SigE content resulted in enhanced recruitment of SigE during nitrogen recovery, especially in early phase (Fig. $7 \mathrm{~g}$ and $\mathrm{h}$ ).

\section{Discussion}

6S RNA promotes the recovery process from $\mathrm{N}$ starvation The acclimation processes of cyanobacteria to changing nitrogen availability are underlain by a complex regulatory network, involving signal-driven transcriptional regulons and differential $\sigma$ factor activity, refined with a layer of sRNA-mediated post-transcriptional regulation [48-50].

Here we demonstrate that the cyanobacterial 6S RNA homologue plays a role within the transcriptional response during recovery from nitrogen depletion. The 


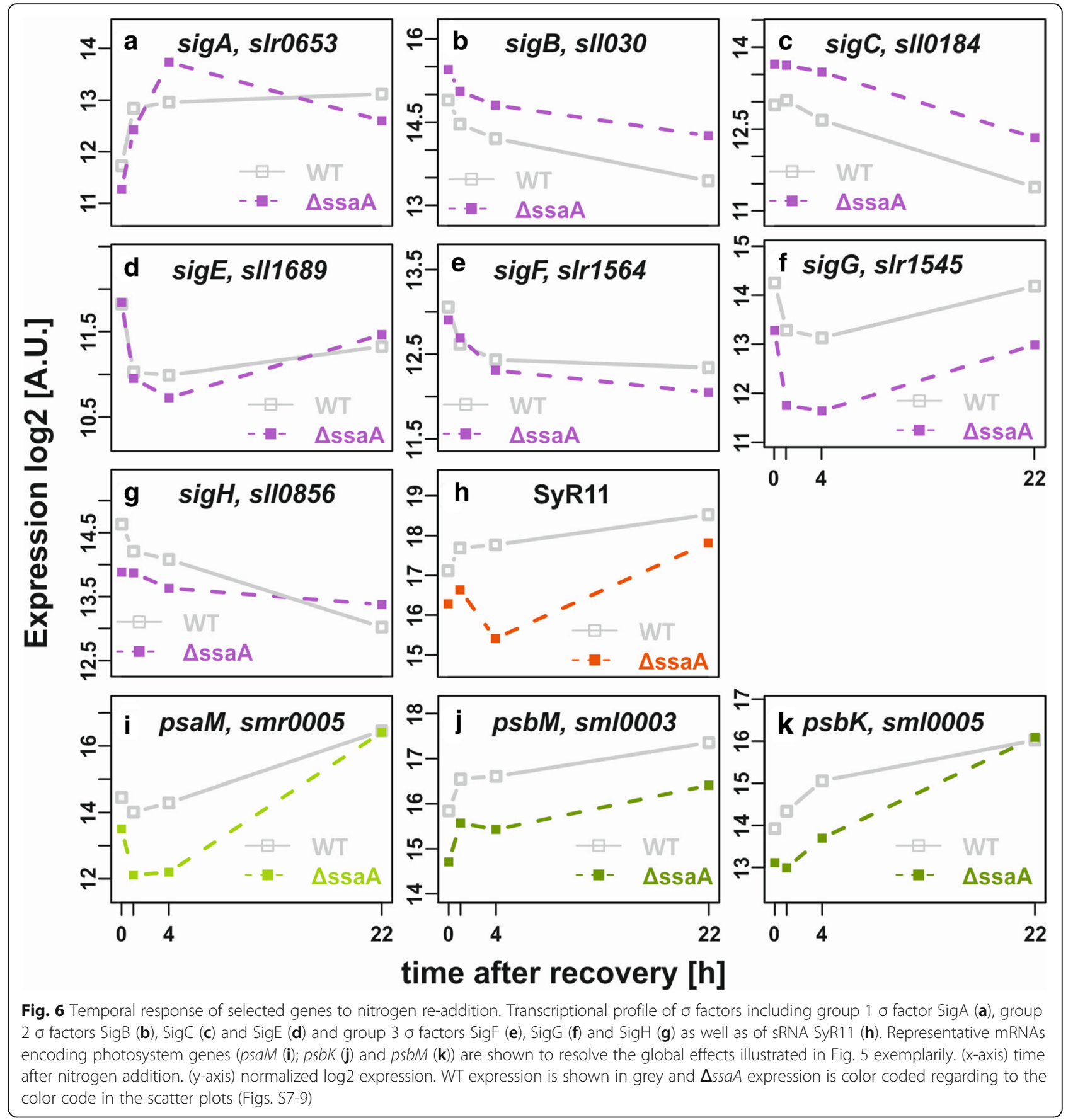

$\Delta s s a A$ mutant of Synechocystis 6803 showed a more sustained bleaching phenotype linked with a generally decelerated transcriptional and physiological response during recovery. Thus, within this gradual acclimation process 6S RNA containing cells have a substantial selective advantage over cells missing $6 \mathrm{~S}$ RNA. On the other hand, overproduction of 6S RNA in Synechocystis 6803 did not accelerate recovery from nitrogen starvation, suggesting that this riboregulator is not a limiting factor in the native acclimation system.
The behavior of 6S RNA during nitrogen-deficiencyinduced bleaching and subsequent recovery in Synechocystis 6803 differs from that reported for stationary phase in heterotrophic bacteria. In Synechocystis 6803, 6S RNA increases only slightly during nitrogen starvation (Fig. 4a) and 6S RNA is quite abundant under standard conditions [46, 51]. For the cyanobacterium Synechococcus sp. PCC 6301 it has been reported previously, that $6 \mathrm{~S}$ RNA levels decrease during stationary phase [31]. In E. coli, 6S RNA molecules enrich 10-fold 




from early exponential growth phase to late stationary phase [19] and binding of RNAP- $\sigma^{70}$ holoenzyme to $6 \mathrm{~S}$ RNA keeps the RNAP- $\sigma^{70}$ holoenzyme complex abundant although it becomes inactive. The importance of the regulatory function of 6S RNA in E. coli is obvious as deletion of 6S RNA affects expression of $\sim 800$ genes in stationary 
phase. Contrary to that, $6 \mathrm{~S}$ RNA might play only a minor role in nitrogen starved Synechocystis 6803 cells as only very few genes show different expression in nitrogen starved WT and $\triangle s s a A$ cells (Additional file 1: Figure S6). Furthermore, the amount of the RNAP-SigA complex drastically reduces during nitrogen starvation in Synechocystis 6803 indicating that formation of inactive RNAPSigA-6S RNA holoenzyme complexes is not the main regulatory mechanism behind reduced transcription of household genes. It is possible that 6S RNA exhibits some functional diversity within different bacterial phyla. Interestingly, Bacillus subtilis produces two different 6S RNAs, 6S-1 RNA and 6S-2 RNA [52]. The 6S-1 RNA (bsrA) is highly upregulated in stationary phase just like 6S RNA in $E$. coli while 6S-2 RNA (bsrB) transcript level decrease towards stationary phase [53]. Therefore, Synechocystis 6803 6S RNA possibly resembles 6S-2 RNA in matters of transcriptional regulation.

In accordance with the physiological data, transcriptome profiling demonstrated that particularly genes encoding ATP synthase, PSI and PSII and phycobilisomes as well as the translational machinery were overall negatively affected by the absence of 6S RNA during recovery from nitrogen starvation. The resuscitation process from severe long-term nitrogen starvation has recently been described in detail for Synechocystis 6803 by Klotz and co-workers [43]. The recovery process from nitrogen starvation can be divided into two phases. Phase 1 is characterized by regeneration of basic cellular functions, including respiration, translation and nitrogen assimilation, which could be clearly confirmed by our transcriptome study. Here, certainly expression of ATP synthase and ribosomal genes showed a delay of general upshift from $1 \mathrm{~h}$ to $4 \mathrm{~h}$ after nitrogen addition in the $\triangle s s a A$ mutant. The kinetics of photosynthesis-related mRNA accumulation further emphasizes the generally delayed recovery: the early phase 2 response, which is partially initiated after $4 \mathrm{~h}$ in WT, rather arises later in the mutant, largely approaching WT levels after $22 \mathrm{~h}$. Moreover, due to delayed transcriptional activation of phase 1 and phase 2 genes, recovery of physiological processes like phycobilisome reassembly, photosynthetic activity and glycogen degradation were delayed in $\triangle s s a A$.

Our results show that 6S RNA has an effect on the recruitment of $\sigma$ factors especially during early recovery from nitrogen depletion but does not affect expression of NtcA controlled genes like $a m t 1, g \ln A, g \ln B$ or $\operatorname{sig} E$, indicating an additional regulatory circuit that acts independently and putatively supplementary to the wellcharacterized PipX-PII-NtcA network [44]. Although none of the group $2 \sigma$ factors alone is essential for acclimation to nitrogen deficiency and subsequent recovery, cells without functional group $2 \sigma$ factors were more sensitive to nitrogen depletion [40].
During recovery from nitrogen depletion WT cells recruited SigA more efficiently than $\triangle s s a A$ cells, indicating that SigA recruitment was promoted by $6 \mathrm{~S}$ RNA when cells switched from nitrogen depletion to repletion.

The amount of RNAP-SigC increased in both strains during nitrogen deficiency and in the beginning of recovery phase. However, the SigC recruitment during the early recovery phase was considerably more pronounced in $\triangle s s a A$ than in WT. Cells containing SigC as the only functional group $2 \sigma$ factor (the $\triangle \operatorname{sig} B D E$ strain) showed a delayed recovery from nitrogen starvation [40] and $\mathrm{SigC}$ has been suggested to regulate nitrogen metabolism in stationary phase [54]. Altogether, these results suggest that recruitment of SigC by RNAP core prevent exit of cells from the stress-adapted state.

Likewise, SigB was recruited in larger quantities in $\triangle s s a A$ at the beginning of recovery. Cells without stress inducible $\mathrm{SigB}$ are vulnerable to many stress conditions including heat [55] and high salt [56, 57], and SigB helps to keep photosynthesis active under nitrogen deficiency [40]. It remains to be elucidated which role SigB might play in activation of the sigA gene during recovery from nitrogen deficiency induced stationary phase. However, a possible connection can be derived from previous experiments with dark/ light transitions [58].

The amount of SigE increases during nitrogen starvation and early recovery in both strains (Fig. 7h). However, the recruitment of SigE was less efficient in $\Delta s s a A$ than in WT in the early recovery phase. SigE has been earlier suggested to function in nitrogen stress responses $[36,39]$, and its role in triggering sugar catabolism is well-characterized [39, 41, 59]. Since $g l g X$ and $g l g P$ are positively controlled by SigE [60], the observed effect on SigE recruitment might underlie the decelerated glycogen degradation of the mutant strain. An anti- $\sigma$ factor, $\mathrm{ChlH}$, has been proposed to inhibit SigE recruitment in a lightdependent manner [61]. Moreover, the sRNA SyR11, which is presumably involved in post-transcriptional activation of sigE expression (unpublished results), showed significantly reduced levels in $\Delta s s a A$, particularly during early recovery. Therefore, more detailed research on the involvement of integrated post-translational effects and certainly - riboregulatory events will further disclose the complexity of the cyanobacterial $\sigma$ factor network during physiological transitions. While not a conspicuous feature in this comparative study, the asRNA slr0653-as4 appears to be a potent inhibitor of sigA expression during starvation [43], exemplifying the significance of the RNAregulatory layer in this process.

\section{Conclusion}

Based on our current knowledge, we postulate a possible mechanism for 6S RNA-dependent regulation within the acclimation process to changing nitrogen supply in 
Synechocystis 6803. Formation of RNAP-SigA holoenzymes drastically decreases during nitrogen deprivation while recruitment of different group $2 \sigma$ factors either increases (SigC and SigE) or remains at the same level (SigB and SigD) as under standard conditions. After prolonged nitrogen deficiency, transcription activity is low in general [43], most probably because expression of household genes is depressed due to low formation of RNAP-SigA holoenzymes. During the recovery phase, group $2 \sigma$ factors are first to be efficiently recruited by RNAP core, in order to be replaced later on by the primary $\sigma$ factor. This replacement process appears to be facilitated by 6S RNA. Due to a delayed formation of RNAP-SigA holoenzymes in the $\triangle s s a A$ strain, activation of many household genes occurs at a slower rate resulting in a decelerated re-synthesis and activation of light harvesting and photosynthetic complexes.

However, comprehensive binding studies and in vitro transcription analysis will be necessary to provide evidence for the direct regulatory impact of 6S RNA on $\sigma$ factor dynamics in Synechocystis 6803. Thus far, this RNA was shown to functionally substitute for its homologue from E. coli in vitro, as it binds to $E$. coli RNAP, exhibits inhibitory activity on transcription and serves as a template for pRNA synthesis [28]. According studies of the native system - considering the plurality of group $2 \sigma$ factors - will certainly help to elucidate the mechanistic features of 6S RNA mediated transcriptional response to nitrogen availability in cyanobacteria.

\section{Methods}

\section{Bacterial strains, growth conditions and experimental setup}

The Synechocystis sp. PCC 6803 strain PCC-M [62] used in this study was provided by S. Shestakov (Moscow State University) and cultivated on 1\% $(w / v)$ agar (Bacto agar; Difco) plates containing BG-11 mineral medium [63]. Liquid cultures of WT and mutant strains were grown in BG-11 medium containing $10 \mathrm{mM}$ TES buffer, $\mathrm{pH}$ 8.0, under continuous illumination with white light at 40-80 $\mu \mathrm{mol}$ photons $\mathrm{m}^{-2} \mathrm{~s}^{-1}$ at $30{ }^{\circ} \mathrm{C}$, supplemented with a continuous stream of ambient air. BG11 plates for the cultivation of mutant strains were supplemented with $40 \mu \mathrm{g} \mathrm{ml}^{-1}$ kanamycin $(\Delta s s a A)$ and $10 \mu \mathrm{g} \mathrm{ml} \mathrm{m}^{-1}$ chloramphenicol (WT-RNAP-HIS) or both antibiotics ( $\Delta s a A$-RNAP-HIS), respectively. No antibiotics were added to the liquid cultures. Deviating growth conditions are specified in the corresponding figure legends or in the text. For nitrogen depletion, $\mathrm{NaNO}_{3}$ was omitted from the medium and cells were first washed twice and then resuspended in nitrogen-free medium. Cultures were incubated in nitrogen-depleted medium for 38 days. To induce nitrogen recovery, starved cells were supplemented with $17.6 \mathrm{mM} \mathrm{NaNO}$. Cells were harvested after cultivation in nitrogen-repleted medium for the indicated times $(1 \mathrm{~h}, 4 \mathrm{~h}, 22 \mathrm{~h}, 48 \mathrm{~h}, 144 \mathrm{~h})$.

\section{Construction of 6S RNA mutants and RNAP-HIS mutants}

For the construction of a $6 \mathrm{~S}$ RNA deletion mutant $(\triangle s s a A)$ the whole ssaA gene of Synechocystis 6803 was deleted by replacement with a kanamycin-resistance cassette $\left(\mathrm{Km}^{\mathrm{R}}\right)$. As distinguished from the previously described $\Delta s s a A$ mutant [32], the entire $\mathrm{Km}^{\mathrm{R}}$ cassette from cloning vector pUC4K [64] harboring its own promoter was used for replacement of the chromosomal ssaA locus $(1,886,879 . .1887066)$. The construct was prepared by overlap extension PCR of three fragments: (i) $697 \mathrm{bp}$ region upstream of $s s a A$ to chromosomal nucleotide position 1,886,182 (primer pair slr1288_fw/ 3'slr1288_rv, cf. Additional file 1: Table S1), (ii) $1027 \mathrm{bp} \mathrm{Km}^{\mathrm{R}}$ cassette including $15 \mathrm{bp}$ overhangs at both termini (primer pair $\mathrm{Km} \_\mathrm{fw} / \mathrm{Km} \_r v$ ), and (iii) 699 bp downstream of $s s a A$ to chromosomal nucleotide position 1,887,765 (primer pair sll1166_fw/ 3'sll1166_rv). The $\sim 700$ bp flanking regions contained non-disrupted segments of loci slr1288 and sll1166, and were used for homologous recombination. The $\Delta s s a A$-mutant was selected on BG11 agar plates containing $50 \mu \mathrm{g} \mathrm{ml}^{-1}$ kanamycin. PCR analysis was used to verify complete segregation of WT chromosomal copies (Fig. 1b). The primers P1 ( $\left.\Delta s s a A_{-} 700 u p \_f w\right)$ and P2 ( $\triangle$ ssaA_700down_rv) are listed below in Additional file 1: Table S1. To create a strain overexpressing $6 \mathrm{~S}$ RNA $(6 \mathrm{~S}(+))$, the $s s a A$ gene locus and its promoter region ( 150 bp of upstream region) were inserted into the self-replicating vector pVZ321 [65], containing a chloramphenicol resistence gene using XhoI and Xbal. The vector was then transferred to WT cells by conjugation. Exconjugants were selected on BG11 agar plates containing $10 \mu \mathrm{g} \mathrm{ml}^{-1}$ chloramphenicol. Complementation of the $\triangle s s a A$ strain $(\triangle s s a A-c)$ was achieved by transferring the pVZ321 vector containing the $s s a A$ gene plus $\sim 150$ bp of its upstream region and a chloramphenicol resistance gene to $\triangle s s a A$ mutant cells by conjugation [64]. The $\triangle s s a A$-c-mutant was selected on BG11 agar plates containing $50 \mu \mathrm{g} \mathrm{ml}^{-1}$ kanamycin and $10 \mu \mathrm{g}$ $\mathrm{ml}^{-1}$ chloramphenicol. For the generation of a WTRNAP-HIS and $\triangle s s a A$-RNAP-HIS mutant strain, Synechocystis $6803 \mathrm{WT}$ and $\triangle$ ssaA cells were transformed using the plasmid pC-HIS-rpoC1-CAP-I-I (containing a nine amino acids long His-tag attached to the $\mathrm{C}$ terminal end of the $\gamma$ subunit, and a chloramphenicol resistance cassette after the rpoC1 gene) which was described earlier by Koskinen et al. [47]. WT-RNAP-HIS and $\Delta s s a A$ RNAP-HIS mutants were probed on BG11 plates containing $10 \mu \mathrm{g} \mathrm{ml}^{-1}$ chloramphenicol and full segregation of the mutants was tested by PCR analysis using primers rpoC1His5 and rpoC1His6 (Additional file 1: Table S1) from Koskinen et al. [47]. 


\section{Analysis of growth, pigmentation and photosynthetic capacity}

Whole cell absorbance spectra were recorded from 400 to $750 \mathrm{~nm}$ on a Specord 200 PLUS spectrophotometer (Analytik Jena, Jena, Germany) and were corrected for a residual scattering at $750 \mathrm{~nm}$. Chlorophyll was extracted in $90 \%$ methanol and the content was measured by spectrophotometry [66]. Contents of phycocyanin and allophycocyanin were determined in the soluble protein fraction according to Tandeau de Marsac and Houmard [66]. The pigment contents were normalized to the optical density at $750 \mathrm{~nm}$. Photosynthetic capacity of cells was measured as light saturated oxygen evolution rates with a Clark-type oxygen electrode (Hansatech) in BG11 medium in vivo in the presence of $10 \mathrm{mM} \mathrm{NaHCO}$ at $32{ }^{\circ} \mathrm{C}$, illuminated with white light (photosynthetic photon flux density $3000 \mu \mathrm{mol} \mathrm{m} \mathrm{m}^{-2} \mathrm{~s}^{-1}$ ) [56]. In measurements of the maximum rate of photosynthesis, oxygen production by PSII is limited by the Calvin-Benson cycle, and addition of $\mathrm{NaHCO}_{3}$ allows the cycle to function at its maximal rate. To determine PSII capacity, the samples were supplemented with artificial electron acceptor 2,6-dimethoxybenzoquinone (DMBQ, $1 \mathrm{mM}$ ) and ferricyanide $(1 \mathrm{mM})$. These chemicals are added in excess, and thus electron transfer through PSII is limited only by the maximum rate of PSII itself. In preparation for $77 \mathrm{~K}$ fluorescence emission spectroscopy, cells were concentrated to $35 \mu \mathrm{g} \mathrm{Chl} \mathrm{ml}{ }^{-1}$, and $50 \mu \mathrm{l}$ samples were immediately frozen in liquid nitrogen. The fluorescence was measured at $77 \mathrm{~K}$ with orange light excitation (580 nm) using an Ocean Optics S2000 spectrometer. The spectra were corrected with a moving median, subtraction of the dark level and division by the peak value of PSI at $721 \mathrm{~nm}$ and setting this value to 1 . Differences in chlorophyll, allophycocyanin and phycocyanin content as well as of oxygen evolution rates were statistically analyzed using one-way ANOVA.

\section{Determination of glycogen content}

The content of glycogen per $\mathrm{ml}$ cell suspension was determined as described by Gründel et al. [67]. Cell pellets of $0.5-1.5 \mathrm{ml}$ culture were suspended in $30 \%(w / v)$ $\mathrm{KOH}$ and incubated for $2 \mathrm{~h}$ at $95{ }^{\circ} \mathrm{C}$. An addition of icecold ethanol to a final concentration of $75 \%(\mathrm{v} / \mathrm{v})$ and a following incubation on ice for at least $1.5 \mathrm{~h}$ were required for the precipitation of glycogen. The isolated glycogen was centrifuged for $15 \min \left(16,000 \mathrm{~g}, 4{ }^{\circ} \mathrm{C}\right)$ and the pellet was washed with $70 \%$ and $98 \%(\mathrm{v} / \mathrm{v})$ ice-cold ethanol and dried for $10 \mathrm{~min}$ at $60{ }^{\circ} \mathrm{C}$. For the enzymatic hydrolysis of glycogen to glucose, the pellet was suspended in $100 \mathrm{mM}$ sodium acetate $(\mathrm{pH} 4.5)$ including $2 \mathrm{mg} / \mathrm{ml}$ amyloglycosidase and incubated for $4 \mathrm{~h}$ at $95^{\circ}$ C. To determine the content of glucose, a hexokinase reagent was used according to the manufacturer's protocol and measured spectrophotometrically.

\section{Isolation of RNA polymerase complex and immunoblot analysis}

Cells from WT-RNAP-HIS and $\triangle s s a A$-RNAP-HIS mutant strain $\left(50 \mathrm{ml}, \mathrm{OD}_{750 \mathrm{~nm}}=0.8-1.1\right)$ were collected from growth at standard conditions, after $6 \mathrm{~d}$ of growth in nitrogen depleted medium or after $1 \mathrm{~h}, 4 \mathrm{~h}$ and $22 \mathrm{~h}$ of recovery in nitrogen replete medium. The samples were broken and the soluble protein fraction was obtained as described in Koskinen et al. [47]. For the isolation of RNAP the Dynabeads ${ }^{\oplus}$ HIS-Tag Isolation and Pulldown Kit was applied according to the manufacturer's instructions. $900 \mu \mathrm{g}$ of soluble protein fraction was used for the pulldown and RNAP complexes were eluted to $75 \mu \mathrm{l}$ of elution buffer [47]. $10 \mu \mathrm{l}$ of His-tag purified RNAP samples were subjected to $10 \%$ NEXT GEL SDS-PAGE according to the protocol of Koskinen et al. [47]. RNAP complexes were transferred to Immobilon-P membrane using the semidry blotting method followed by incubation with specific polyclonal antibodies against $\sigma$ factors SigA, SigB, SigC and SigE $[47,68,69]$. Proteins were visualized and quantified as described by Koskinen et al. [47]. Membranes were reprobed with antibodies against $\alpha$ or $\beta$ subunits of the RNAP core [69] and the $\sigma$ factor content was normalized to $\alpha$ (SigA, SigC, SigE) or $\beta$ subunit content (SigB). Similarly, $5 \mu \mathrm{g}$ of soluble proteins for SigA, $25 \mu \mathrm{g}$ for SigB, $15 \mu \mathrm{g}$ for SigC and $25 \mu \mathrm{g}$ for SigE were used for separation on SDS-PAGE and were detected as described above.

\section{RNA isolation and northern blot hybridization}

For the isolation of RNA, samples from discrete stages of cultivation were taken at the indicated times and were immediately put on ice and spun down at $4{ }^{\circ} \mathrm{C}$. The preparation of total RNA from Synechocystis 6803 was essentially performed as described previously [70], using the Hot Trizol method, followed by 2-propanol precipitation. To determine the concentration and to check the quality of total RNA, we made use of a NanoDrop N10000 spectrophotometer and electrophoretic separation on 1.3\% agarose-formaldehyde gels. For Northern Blot detection, RNA samples were separated by electrophoresis either on $1.3 \%$ agarose-formaldehyde gels or $10 \%$ polyacrylamide-urea gels (urea-PAGE) and transferred to Hybond $^{\text {TM }}-\mathrm{N}^{+}$membranes. The correct deletion of the ssaA gene was tested by northern blot analysis using a directed $\left[{ }^{32} \mathrm{P}\right]$-labelled DNA oligonucleotide for 6S RNA. Alternatively, digoxigenin (DIG)-labelled RNA oligonucleotides (riboprobes) for 6S RNA, 5S rRNA as well as for SyR11 were used to analyze RNA accumulation levels. DIG-labelled riboprobes were prepared 
according to the manufacturer's instructions using in vitro transcription with the AmpliScribe kit (T7Flash Transcription kit, Epicentre) from a PCR product containing a T7 promotor. The PCR fragment was amplified with the primer pairs 6803ssaA-FwS/ T7-6S_6803_rev, 5S_6803_fw/ T7-5S_6803_rev and SyR11_fw/ SyR11_T7_rev, respectively (Additional file 1: Table S1).

Riboprobe hybridization was accomplished by overnight incubation at $62{ }^{\circ} \mathrm{C}$, followed by chemiluminescent immunodetection using the DIG Northern Starter Kit (Roche).

\section{Microarray analysis}

The microarray design, hybridization procedure and data analysis have been described previously [71]. The array is a whole genome gene expression array covering all known RNA features from tiling array microarray and dRNAseq transcriptome studies [46, 71]. Each feature is covered by up to four individual probes. All probes exist as technical replicates. For the microarray analysis total RNA samples from two biological replicates were used. Raw data were processed with the $\mathrm{R}$ package limma. Median signal intensity was cyclic loess normalized. The $p$ values were generated by limma [72] and adjusted for multiple testing with the Benjamini Hochberg method.

\section{Additional files}

Additional file 1: Table S1. Sequences of primers used for construction and PCR-based verification of $\triangle$ ssaA- and HIS-mutant strains, as well as for PCR-based generation of riboprobe templates. Figure S1. Pairwise comparison of whole cell absorbance spectra of Synechocystis 6803 WT and $\triangle$ ssaA strain shown in Fig. 2c. Figure S2.Photosynthetic parameters of wild type (WT) and $\triangle s s a A$ mutant during nitrogen starvation. Figure S3. Verification of the genetic complementation of ssaA gene disruption. Figure S4. Pigment analysis of WT and $\Delta s s a A$. Figure S5. Glycogen consumption during recovery from nitrogen starvation. Figure $\mathbf{S 6}$. Volcanoplot showing the gene expression differences in $\mathrm{WT}$ and $\Delta s s a A$ after prolonged nitrogen depletion and before nitrogen re-addition $\left(t_{1}=0 \mathrm{~h}+\mathrm{N}\right)$. Figure S7. Expression patterns of transcripts with significantly altered levels in the $\Delta$ ssaA mutant strain at early recovery from nitrogen depletion $\left(t_{2}=1 \mathrm{~h}+\mathrm{N}\right)$. Figure S8. Expression patterns of transcripts with significantly altered levels in the $\Delta s s a A$ mutant strain at recovery from nitrogen depletion $\left(t_{3}=4 \mathrm{~h}+\right.$ N.). Figure S9. Expression patterns of transcripts with significantly altered levels in the $\Delta s s a A$ mutant strain at recovery from nitrogen depletion $\left(t_{4}=\right.$ $22 \mathrm{~h}+\mathrm{N}$ ). Figure S10. Microarray data analysis showing exemplary details of gene expression in Synechocystis $6803 \mathrm{WT}$ and $\triangle$ ssaA strain (depicted as d6S) at time points $\mathrm{t}_{1}=0 \mathrm{~h}+\mathrm{N}(7 \mathrm{~d}-\mathrm{N}) ; \mathrm{t}_{2}=1 \mathrm{~h}+\mathrm{N}, \mathrm{t}_{3}=4 \mathrm{~h}+\mathrm{N}$ and $\mathrm{t}_{4}=$ $22 \mathrm{~h}+\mathrm{N}$. Figure S11. Validation of Microarray data analysis. Expression of SyR11 in Synechocystis 6803. (DOCX 1909 kb)

Additional file 2: Overview of the genome-wide expression profile of Synechocystis 6803 wild type (WT) and $\triangle$ ssaA (d6S) strain under nitrogen depleted conditions $\left(t_{1}=0 \mathrm{~h}+\mathrm{N}\right)$ and at recovery from nitrogen depletion $\left(\mathrm{t}_{2}=1 \mathrm{~h}+\mathrm{N}, \mathrm{t}_{3}=4 \mathrm{~h}+\mathrm{N}, \mathrm{t}_{4}=22 \mathrm{~h}+\mathrm{N}\right)$ by combining the log2 expression values (left scale) with read numbers of 454 sequencing (right scale). (PDF $42993 \mathrm{~kb}$ )

Additional file 3 Raw data of microarray analysis of Synechocystis 6803 wild type (WT) and $\Delta$ ssaA (d6S) strain. (XLSX $5837 \mathrm{~kb}$ )

\section{Abbreviations}

B. subtilis: Bacillus subtilis; Chl: Chlorophyll $a ; \mathrm{Cm}^{\text {r: }}$ Chloramphenicol resistance cassette; DIG: Digoxygenin; DMBQ: 2,6-dimethoxybenzoquinone; dRNAseq: differential RNA sequencing; E. coli: Escherichia coli; Kmr: Kanamycin resistance cassette; N: Nitrogen; ncRNA: Non-coding RNA; nt: Nucleotide; OD: Optical density; PBS: Phycobilisome; pRNA: Product RNA;

PSI: Photosystem I; PSII: Photosystem II; RNAP: RNA polymerase; sRNA: Small RNA; std: Standard; Synechocystis 6803: Synechocystis sp. PCC 6803; WT: Wild type; $\sigma:$ Sigma factor

\section{Acknowledgements}

We thank Viktoria Reimann for technical support and Anne Rediger for generating the $\Delta s s a A$ mutant and the $6 \mathrm{~S}(+)$ mutant strain.

\section{Funding}

This work was supported by the German Ministry for Education and Research (BMBF) program FORSYS Partner grant number 0315294 to BH and IMA, BMBF grant e:bio RNAsys 0316165 to WRH and Academy of Finland project 265,807 grant to $\mathrm{KH}$ and $\mathrm{T}$. IMA and DD appreciate funding by the DFG grant EXC 1028 and by the European Union project RiboNets. The project RiboNets acknowledges the financial support of the Future and Emerging Technologies (FET) programme within the Seventh Framework Programme for Research of the European Commission, under FET-Open grant number: 323,987.

\section{Availability of data and materials}

The microarray data generated during the current study are available in NCBI's Gene Expression Omnibus (GEO) repository with accession no. GSE83387: https://www.ncbi.nlm.nih.gov/geo/query/acc.cgi?acc=GSE83387

\section{Authors' contributions}

IMA and DD designed and supervised the project. BH carried out all physiological studies, analyzed photosynthetic parameters, prepared RNA for microarray analysis, contributed to the recruitment analysis and performed Northern Blot hybridization. JG and WRH performed the microarray analysis, $\mathrm{KH}$ contributed to the recruitment and soluble protein analysis. BH and DD conducted all verification experiments. DD performed physiological studies and Northern Blot hybridization of the complementation strain ( $\triangle$ ssaA-c). IMA, DD, BH, JG and $T$ interpreted the data. $B H$ and JG prepared the figures. BH, DD, JG, WRH, TT, KH and IMA drafted the manuscript. All authors reviewed and approved the manuscript.

\section{Ethics approval and consent to participate}

Not applicable.

\section{Consent for publication}

Not applicable.

\section{Competing interests}

The authors declare that they have no competing interests.

\section{Publisher's Note}

Springer Nature remains neutral with regard to jurisdictional claims in published maps and institutional affiliations.

\section{Author details}

${ }^{1}$ Institute for Synthetic Microbiology, Cluster of Excellence on Plant Sciences (CEPLAS), Heinrich Heine University Düsseldorf, Universitätsstrasse 1, 40225 Düsseldorf, Germany. ${ }^{2}$ Department of Biochemistry, University of Turku, Fl-20014 Turku, Finland. ${ }^{3}$ Genetics and Experimental Bioinformatics, Faculty of Biology, University of Freiburg, Schänzlestr. 1, 79104 Freiburg, Germany. ${ }^{4}$ Department of Biotechnology, Beuth University of Applied Sciences, Seestr. 64, 13347 Berlin, Germany. ${ }^{5}$ Department of Chemistry - Microbial Chemistry, Ångström and Science for Life Laboratory, Uppsala University, Box 523, SE-751 20 Uppsala, Sweden. 
Received: 10 May 2017 Accepted: 27 November 2017 Published online: 08 December 2017

\section{References}

1. Möllers KB, Cannella D, Jørgensen H, Frigaard N-U. Cyanobacterial biomass as carbohydrate and nutrient feedstock for bioethanol production by yeast fermentation. Biotechnology for Biofuels. 2014;7:64.

2. Dexter J, Armshaw P, Sheahan C, Pembroke JT. The state of autotrophic ethanol production in Cyanobacteria. J Appl Microbiol. 2015;119:11-24.

3. Sarsekeyeva F, Zayadan BK, Usserbaeva A, Bedbenov VS, Sinetova MA, Los DA. Cyanofuels: biofuels from cyanobacteria. Reality and perspectives. Photosynth Res. 2015;125:329-40.

4. Erdrich P, Knoop H, Steuer R, Klamt S. Cyanobacterial biofuels: new insights and strain design strategies revealed by computational modeling. Microb Cell Factories. 2014;13:128.

5. Rögner M. Metabolic engineering of cyanobacteria for the production of hydrogen from water. Biochem Soc Trans. 2013;41:1254-9.

6. Angermayr SA, van der Woude AD, Correddu D, Vreugdenhil A, Verrone V, Hellingwerf KJ. Exploring metabolic engineering design principles for the photosynthetic production of lactic acid by Synechocystis sp. PCC6803. Biotechnology for Biofuels. 2014;7:99.

7. Pattanaik B, Lindberg P. Terpenoids and their biosynthesis in Cyanobacteria. Life. 2015;5:269-93.

8. Ducat DC, Way JC, Silver PA. Engineering cyanobacteria to generate highvalue products. Trends Biotechnol. 2011;29:95-103.

9. Dühring U, Axmann IM, Hess WR, Wilde A. An internal antisense RNA regulates expression of the photosynthesis gene isiA. Proc Natl Acad Sci U S A. 2006:103:7054-8.

10. Hernández-Prieto MA, Schön V, Georg J, Barreira L, Varela J, Hess WR, et al. Iron deprivation in Synechocystis: inference of pathways, non-coding RNAs, and regulatory elements from comprehensive expression profiling. G3. 2012; 2:1475-95.

11. Georg J, Dienst D, Schurgers N, Wallner T, Kopp D, Stazic D, et al. The small regulatory RNA SyR1/PsrR1 controls photosynthetic functions in cyanobacteria. Plant Cell. 2014;26:3661-79.

12. Eisenhut M, Georg J, Klähn S, Sakurai I, Mustila H, Zhang P, et al. The antisense RNA As1_flv4 in the Cyanobacterium Synechocystis sp. PCC 6803 prevents premature expression of the flv4-2 Operon upon shift in inorganic carbon supply. J Biol Chem. 2012;287:33153-62.

13. Gierga G, Voss B, Hess WR. Non-coding RNAs in marine Synechococcus and their regulation under environmentally relevant stress conditions. The ISME Journal. 2012;6:1544-57.

14. Klähn S, Schaal C, Georg J, Baumgartner D, Knippen G, Hagemann M, et al. The sRNA NsiR4 is involved in nitrogen assimilation control in cyanobacteria by targeting glutamine synthetase inactivating factor IF7. Proc Natl Acad Sci U S A. 2015:112:E6243-E52.

15. Barrick JE, Sudarsan N, Weinberg Z, Ruzzo WL, Breaker RR. 6S RNA is a widespread regulator of eubacterial RNA polymerase that resembles an open promoter. RNA. 2005;11:774-84.

16. Steuten B, Hoch PG, Damm K, Schneider S, Kohler K, Wagner R, et al. Regulation of transcription by $6 \mathrm{~S}$ RNAs: insights from the Escherichia Coli and Bacillus Subtilis model systems. RNA Biol. 2014;11:508-21.

17. Cavanagh AT, Wassarman KM. 6S RNA, a global regulator of transcription in Escherichia Coli, Bacillus Subtilis, and beyond. Annu Rev Microbiol. 2014;68:45-60.

18. Burenina OY, Elkina DA, Hartmann RK, Oretskaya TS, Kubareva EA. Small noncoding 6S RNAs of bacteria. Biochem Mosc. 2015;80:1429-46.

19. Wassarman KM, Storz G. 6S RNA Regulates E. Coli RNA polymerase activity. Cell. 2000;101:613-23.

20. Trotochaud AE, Wassarman KM. 6S RNA function enhances long-term cell survival. J Bacteriol. 2004;186:4978-85.

21. Cavanagh AT, Klocko AD, Liu X, Wassarman KM. Promoter specificity for 6S RNA regulation of transcription is determined by core promoter sequences and competition for region 4.2 of sigma(70). Mol Microbiol. 2008:67:1242-56

22. Neusser T, Polen T, Geissen R, Wagner R. Depletion of the non-coding regulatory $6 \mathrm{~S}$ RNA in $\mathrm{E}$. Coli causes a surprising reduction in the expression of the translation machinery. BMC Genomics. 2010;11:165.

23. Wassarman KM, Saecker RM. Synthesis-mediated release of a small RNA inhibitor of RNA polymerase. Science. 2006;314:1601-3.
24. Gildehaus N, Neußer T, Wurm R, Wagner R. Studies on the function of the riboregulator $6 \mathrm{~S}$ RNA from E. Coli: RNA polymerase binding, inhibition of in vitro transcription and synthesis of RNA-directed de novo transcripts. Nucleic Acids Res. 2007:35:1885-96.

25. Wurm R, Neußer T, Wagner R. 6S RNA-dependent inhibition of RNA polymerase is released by RNA-dependent synthesis of small de novo products. Biol Chem. 2010;391:187-96.

26. Trotochaud AE, Wassarman KM. 6S RNA regulation of pspF transcription leads to altered cell survival at high pH. J Bacteriol. 2006;188:3936-43.

27. Hoch PG, Burenina OY, Weber MHW, Elkina DA, Nesterchuk MV, Sergiev PV, et al. Phenotypic characterization and complementation analysis of Bacillus Subtilis 65 RNA single and double deletion mutants. Biochimie. 2015;117:87-99.

28. Cavanagh ATSJ, Wassarman KM. Regulation of 65 RNA by pRNA synthesis is required for efficient recovery from stationary phase in $\mathrm{E}$. Coli and $\mathrm{B}$. Subtilis. Nucleic Acids Res. 2012:40:2234-46.

29. Cabrera-Ostertag IJ, Cavanagh AT, Wassarman KM. Initiating nucleotide identity determines efficiency of RNA synthesis from 6S RNA templates in Bacillus Subtilis but not Escherichia Coli. Nucleic Acids Res. 2013;41:7501-11.

30 Axmann IM, Kensche P, Vogel J, Kohl S, Herzel H, Hess WR. Identification of cyanobacterial non-coding RNAs by comparative genome analysis. Genome Biol. 2005;6:R73.

31 Watanabe T, Sugiura M, Sugita M. A novel small stable RNA, 6Sa RNA, from the cyanobacterium Synechococcus sp. strain PCC6301. FEBS Lett. 1997:416:302-6.

32 Rediger A, Geissen R, Steuten B, Heilmann B, Wagner R, Axmann IM. 6S RNA - an old issue became blue-green. Microbiology. 2012;158:2480-91.

33 Allen MM, Smith AJ. Nitrogen chlorosis in blue-green algae. Arch Mikrobiol. 1969;69:114-20.

34 Collier JL, Grossman AR. Chlorosis induced by nutrient deprivation in Synechococcus sp. strain PCC 7942: not all bleaching is the same. J Bacteriol. 1992;174:4718-26.

35 Görl M, Sauer J, Baier T, Forchhammer K. Nitrogen-starvation-induced chlorosis in Synechococcus PCC 7942: adaptation to long-term survival. Microbiology. 1998;144(Pt 9):2449-58.

36 Krasikov V, Aguirre von Wobeser E, Dekker HL, Huisman J, Matthijs HC. Time-series resolution of gradual nitrogen starvation and its impact on photosynthesis in the cyanobacterium Synechocystis PCC 6803. Physiol Plant. 2012;145:426-39.

37 Llácer JL, Espinosa J, Castells MA, Contreras A, Forchhammer K, Rubio V. Structural basis for the regulation of NtcA-dependent transcription by proteins PipX and PII. Proc Natl Acad Sci U S A. 2010;107:15397-402.

38 Imamura S, Tanaka K, Shirai M, Asayama M. Growth phase-dependent activation of nitrogen-related genes by a control network of group 1 and group 2 sigma factors in a cyanobacterium. J Biol Chem. 2006;281:2668-75.

39 Muro-Pastor AM, Herrero A, Flores E. Nitrogen-regulated group 2 sigma factor from Synechocystis sp. strain PCC 6803 involved in survival under nitrogen stress. J Bacteriol. 2001;183:1090-5.

40 Antal T, Kurkela J, Parikainen M, Kårlund A, Hakkila K, Tyystjärvi E, et al. Roles of group 2 sigma factors in acclimation of the cyanobacterium Synechocystis sp. PCC 6803 to nitrogen deficiency. Plant Cell Physio. 2016;57:1309-18.

41 Osanai T, Imamura S, Asayama M, Shirai M, Suzuki I, Murata N, et al. Nitrogen induction of sugar catabolic gene expression in Synechocystis sp. PCC 6803. DNA Res. 2006:13:185-95.

42 Aguirre von Wobeser E, Ibelings BW, Bok J, Krasikov V, Huisman J Matthijs HCP. Concerted changes in gene expression and cell physiology of the Cyanobacterium Synechocystis sp. strain PCC 6803 during transitions between nitrogen and light-limited growth. Plant Physiol. 2011;155:1445-57.

43 Klotz A, Georg J, Bucinska L, Watanabe S, Reimann V, Januszewski W, et al. Awakening of a dormant Cyanobacterium from nitrogen Chlorosis reveals a genetically determined program. Curr Biol. 2016;26: 2862-72

44 Sauer J, Schreiber U, Schmid R, Volker U, Forchhammer K. Nitrogen starvation-induced chlorosis in Synechococcus PCC 7942. Low-level photosynthesis as a mechanism of long-term survival. Plant Physiol. 2001; 126:233-43.

45 de Porcellinis AJ, Klahn S, Rosgaard L, Kirsch R, Gutekunst K, Georg J, et al. The non-coding RNA Ncr0700/PmgR1 is required for Photomixotrophic growth and the regulation of glycogen accumulation in the Cyanobacterium Synechocystis sp. PCC 6803. Plant Cell Physiol. 2016;57: 2091-103. 
46 Mitschke J, Georg J, Scholz I, Sharma CM, Dienst D, Bantscheff J, et al. An experimentally anchored map of transcriptional start sites in the model cyanobacterium Synechocystis sp. PCC6803. Proc Natl Acad Sci U S A. 2011; 108:2124-9.

47 Koskinen S, Hakkila K, Gunnelius L, Kurkela J, Wada H, Tyystjärvi T. In vivo recruitment analysis and a mutant strain without any group $2 \sigma$ factor reveal roles of different $\sigma$ factors in cyanobacteria. Mol Microbiol. 2016;99:43-54.

48 Schwarz R, Forchhammer K. Acclimation of unicellular cyanobacteria to macronutrient deficiency: emergence of a complex network of cellular responses. Microbiology. 2005;151:2503-14.

49 Osanai T, Ikeuchi M, Tanaka K. Group 2 sigma factors in cyanobacteria. Physiol Plant. 2008;133:490-506.

50 Los DA, Zorina A, Sinetova M, Kryazhov S, Mironov K, Zinchenko W. Stress sensors and signal transducers in cyanobacteria. Sensors (Basel). 2010;10:2386-415.

51 Kopf M, Klahn S, Scholz I, Matthiessen JK, Hess WR, Voss B. Comparative analysis of the primary transcriptome of Synechocystis sp. PCC 6803. DNA Res. 2014;21:527-39.

52 Trotochaud AE, Wassarman KM. A highly conserved 6S RNA structure is required for regulation of transcription. Nat Struct Mol Biol. 2005;12:313-9.

53 Beckmann BM, Burenina OY, Hoch PG, Kubareva EA, Sharma CM, Hartmann RK. In vivo and in vitro analysis of 6S RNA-templated short transcripts in Bacillus Subtilis. RNA Biol. 2011;8:839-49.

54 Asayama MIS, Yoshihara S, Miyazaki A, Yoshida N, Sazuka T, Kaneko T, Ohara O, Tabata S, Osanai T. SigC, the group 2 sigma factor of RNA polymerase, contributes to the late-stage gene expression and nitrogen promoter recognition in the cyanobacterium Synechocystis sp. strain PCC 6803. Biosci Biotechnol Biochem. 2004;68:477-87.

55 Tuominen I, Pollari M, Tyystjärvi E, Tyystjärvi T. The SigB $\sigma$ factor mediates high-temperature responses in the cyanobacterium Synechocystis sp. PCC6803. FEBS Lett. 2006:580:319-23.

56 Pollari M, Gunnelius L, Tuominen I, Ruotsalainen V, Tyystjärvi E, Salminen T, et al. Characterization of single and double inactivation strains reveals new physiological roles for group $2 \sigma$ factors in the Cyanobacterium Synechocystis sp. PCC 6803. Plant Physiol. 2008;147:1994-2005.

57 Nikkinen H-L, Hakkila K, Gunnelius L, Huokko T, Pollari M, Tyystjärvi T. The SigB $\sigma$ factor regulates multiple salt acclimation responses of the Cyanobacterium Synechocystis sp. PCC 6803. Plant Physiol. 2012;158:514-23.

58 Tuominen I, Tyystiärvi E, Tyystiärvi T. Expression of primary sigma factor (PSF) and PSF-like sigma factors in the Cyanobacterium Synechocystis sp. strain PCC 6803. J Bacteriol. 2003;185:1116-9.

59 Nakaya Y, lijima H, Takanobu J, Watanabe A, Hirai MY, Osanai T. One day of nitrogen starvation reveals the effect of sigE and rre37 overexpression on the expression of genes related to carbon and nitrogen metabolism in Synechocystis sp. PCC 6803. J Biosci Bioeng. 2015;120:128-34.

60 Osanai T, Kanesaki Y, Nakano T, Takahashi H, Asayama M, Shirai M, et al. Positive regulation of sugar catabolic pathways in the Cyanobacterium Synechocystis sp. PCC 6803 by the group $2 \sigma$ factor SigE. J Biol Chem. 2005; 280:30653-9.

61 Osanai T, Imashimizu M, Seki A, Sato S, Tabata S, Imamura S, et al. ChIH, the $\mathrm{H}$ subunit of the mg-chelatase, is an anti-sigma factor for SigE in Synechocystis sp. PCC 6803. Proc Natl Acad Sci U S A. 2009;106:6860-5.

62 Trautmann D, Voss B, Wilde A, Al-Babili S, Hess WR. Microevolution in cyanobacteria: re-sequencing a motile substrain of Synechocystis sp. PCC 6803. DNA Res. 2012;19:435-48

63 Rippka R, Deruelles J, Waterbury JB, Herdman M, Stanier RY. Generic assignments, strain histories and properties of pure cultures of cyanobacteria. J Gen Microbiol. 1979;111:1-61.

64 Taylor LA, Rose RE. A correction in the nucleotide sequence of the Tn903 kanamycin resistance determinant in pUC4K. Nucleic Acids Res. 1988;16:358.

65 Zinchenko W, Piven IV, Melnik VA, Shestakov SV. Vectors for the complementation analysis of cyanobacterial mutants. Russ J Genet. 1999;35:228-32

66 Tandeau de Marsac N, Houmard J. Complementary chromatic adaptation: physiological conditions and action spectra. Methods Enzymol. 1988;167:318-28.

67 Gründel M, Scheunemann R, Lockau W, Zilliges Y. Impaired glycogen synthesis causes metabolic overflow reactions and affects stress responses in the cyanobacterium Synechocystis sp. PCC 6803. Microbiology. 2012;158:3032-43.

68 Gunnelius L, Tuominen I, Rantamäki S, Pollari M, Ruotsalainen V, Tyystjärvi $E$, et al. SigC sigma factor is involved in acclimation to low inorganic carbon at high temperature in Synechocystis sp. PCC 6803. Microbiology. 2010;156:220-9.

69 Gunnelius L, Hakkila K, Kurkela J, Wada H, Tyystjärvi E, Tyystjärvi T. The omega subunit of the RNA polymerase core directs transcription efficiency in cyanobacteria. Nucleic Acids Res. 2014;42:4606-14.

70 Dienst D, Duhring U, Mollenkopf HJ, Vogel J, Golecki J, Hess WR, et al. The cyanobacterial homologue of the RNA chaperone $\mathrm{Hfq}$ is essential for motility of Synechocystis sp. PCC 6803. Microbiology. 2008;154:3134-43.

71 Georg J, Voss B, Scholz I, Mitschke J, Wilde A, Hess WR. Evidence for a major role of antisense RNAs in cyanobacterial gene regulation. Mol Syst Biol. 2009;5:305.

72 Ritchie ME, Phipson B, Wu D, Hu Y, Law CW, Shi W, et al. Limma powers differential expression analyses for RNA-sequencing and microarray studies. Nucleic Acids Res. 2015;43:e47-e.

\section{Submit your next manuscript to BioMed Central and we will help you at every step:}

- We accept pre-submission inquiries

- Our selector tool helps you to find the most relevant journal

- We provide round the clock customer support

- Convenient online submission

- Thorough peer review

- Inclusion in PubMed and all major indexing services

- Maximum visibility for your research

Submit your manuscript at www.biomedcentral.com/submit
) Biomed Central 